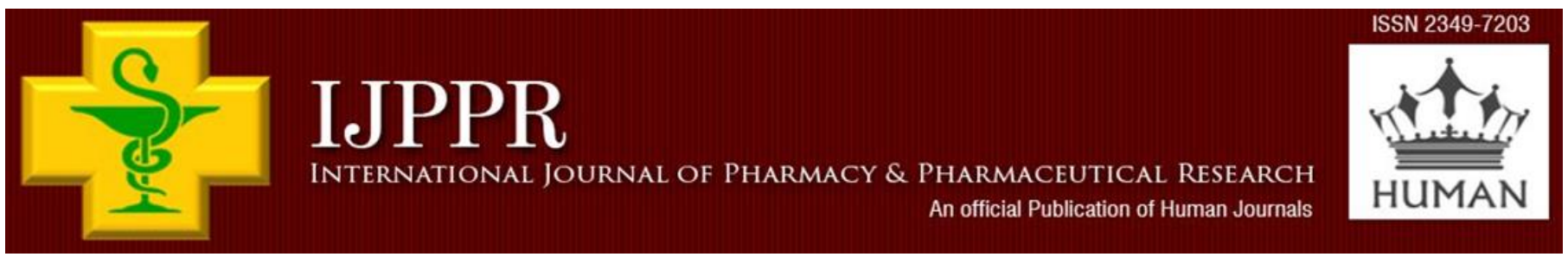

Human Journals

Review Article

March 2019 Vol.:14, Issue:4

(C) All rights are reserved by Ajay Kumar Sahu et al.

\title{
A Literature Review of Control and Prevention of Obesity - A Global Epidemic
}

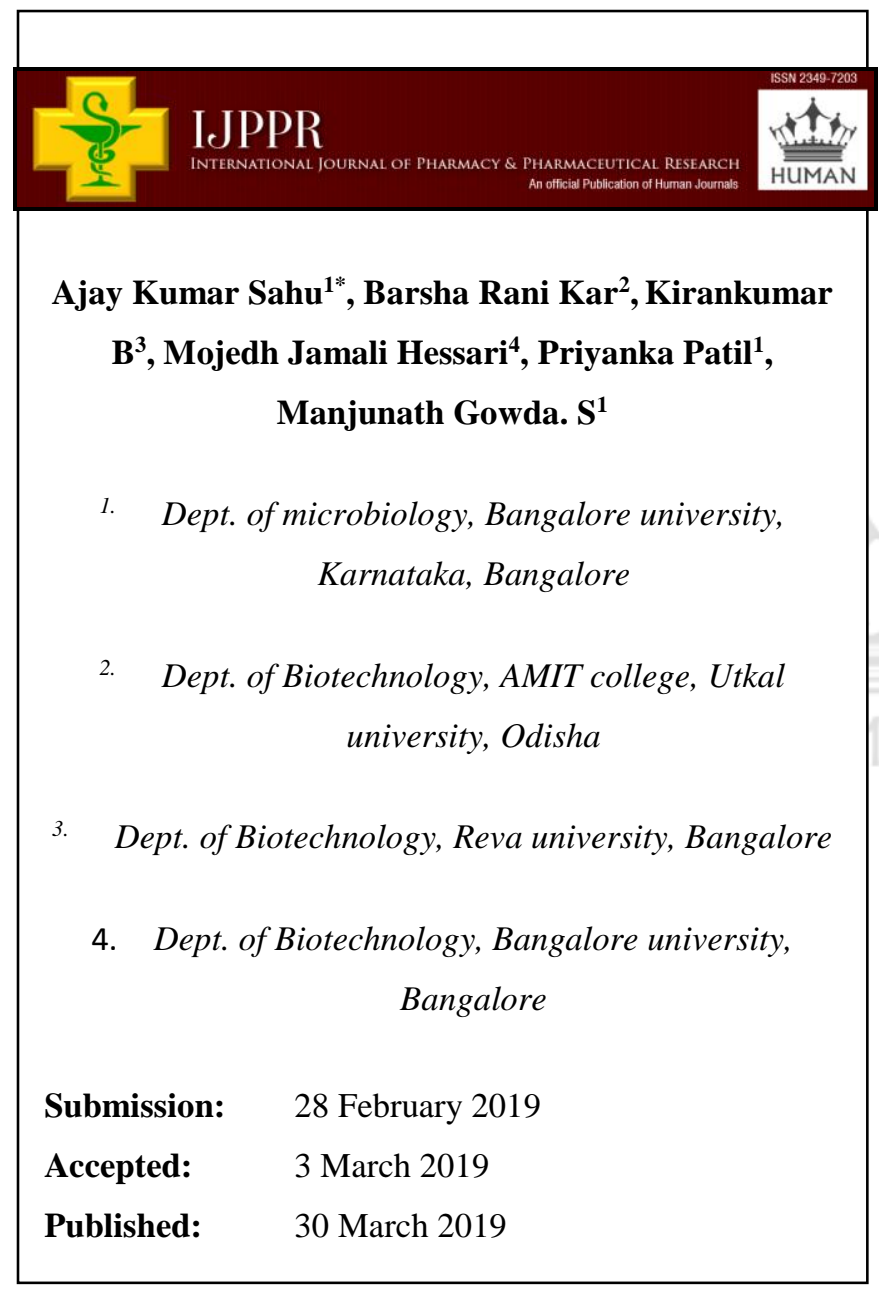
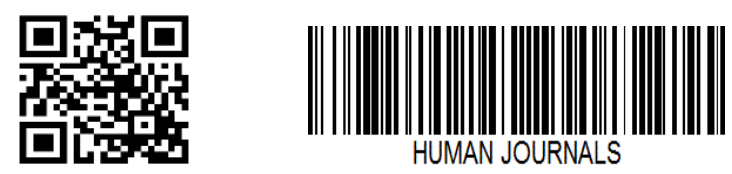

www.ijppr.humanjournals.com
Keywords: Obesity, treatment, control, prevention, global endemic, chronic disease, public health.

\section{ABSTRACT}

Obesity is among the most common and costly chronic disease worldwide. A lack of effective options for long term weight reduction magnifies the enormity of this problem, individuals who successfully complete behavioral and dietary weight loss programs eventually regain most of lost weight. The basic science, clinical and epidemiological literature to assess current knowledge regarding mechanism excess body fat accumulation, the biological defense of excess fat mass and the tendency for lost weight to be regained. A major area of emphasis is the science of energy homeostasis, the biological process that maintains weight stability by actively matching energy intake to energy expenditure over time. The ongoing study of how genetic development and environmental forces affects the energy homeostasis system, growing evidence suggests that obesity is disorder of the energy homeostasis system, rather than simply arising from the passive accumulation of excess weight. Obesity is a chronic metabolic disease characterized by an increase of body fat stores. It is a gateways to ill health and has become one of the leading causes of disability and health problems that affect not only adults but also children and adolescents worldwide. It is important to highlight the available treatment for obesity and to assess their effectiveness, although obesity is an ancient disease, studies are constantly being conducted to improve treatment effectiveness that reduces side effects of any currents medications and identify new therapeutic targets. Because the treatment of obesity is a constantly evolving that treatment can be quite challenging. 


\section{INTRODUCTION}

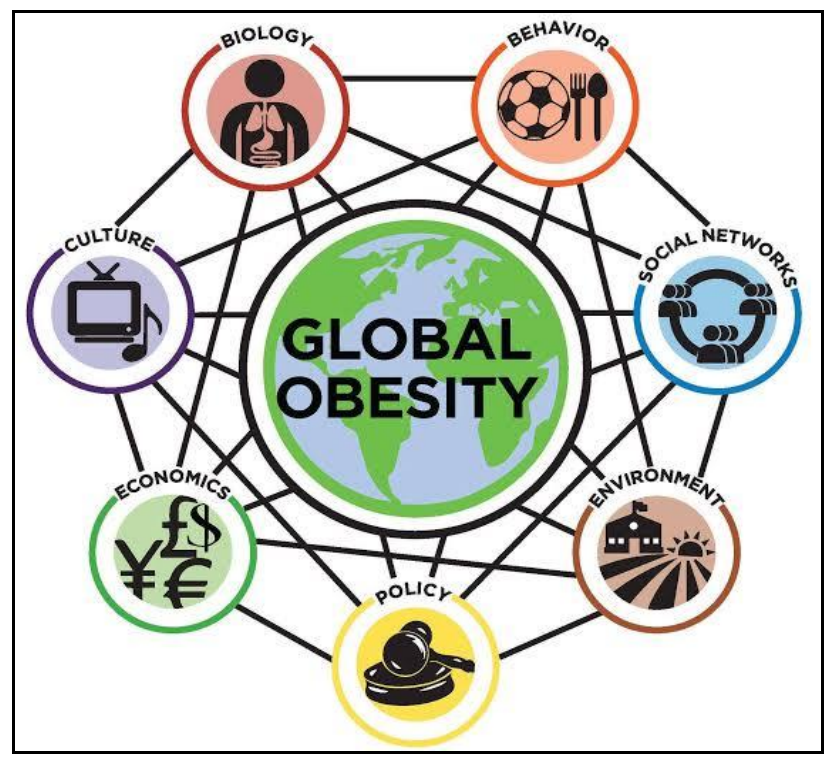

Obesity is a potentially life threatening and chronic disease, as the most metabolic disorder affecting human body, it requires multidisciplinary, long term treatment is essential because obesity has been linked to the onset of many other chronic disease.[1] The currently obesity number reveal properties indicate of worldwide epidemic, obesity is medical condition in which excess body fat has accumulate to the extent that it may have an adverse effect on health that leading to reduce life expectancy and that are increased health problems, according world health organization there will be about 3.3 billion overweight people aged 16 years and above over 800 million obese people worldwide in 2016.[2]

An exhaustive body of literature has emerged to show that overweight and obesity are major causes, including type 2 diabetes, cardiovascular disease and various cancers and health problems which can be lead to morality and mobility. [3]

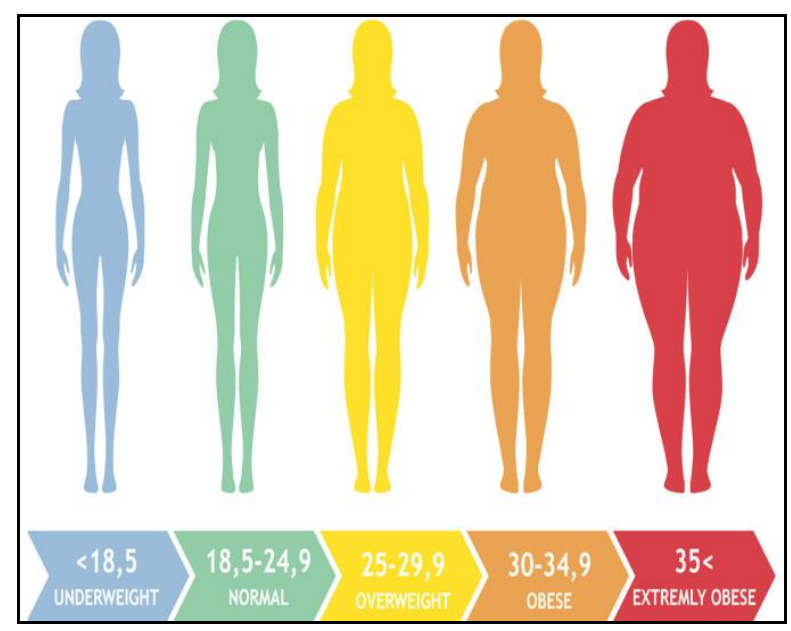




\section{www.ijppr.humanjournals.com}

In Europe, up to 10.5 billion Euros was spent on obesity-related healthcare and the reported relative economic burdens ranged from $0.008 \%$ to $0.006 \%$ of national GDP.

In China, the total medical cost attributes to overweight and costly the obesity was estimated at about 2.54 billion us dollars and these accounted for $3.6 \%$ of national total medical cost in 2004.

The total cost of medical attributes to overweight and obesity in Canada has been estimated to be 0.6 billion us dollars cost of which is $66 \%$ of the attributes of obesity. [4]

\section{Body mass index}

Below 18.5

$18.5-24.8$

$25.0-29.8$

$30.0-34.5$

$35.0-39.9$

$40.0>>>>$

\section{Weight status}

underweight

normal

overweight

obese class 1

obese class 2

extreme obese class 3

BMI provides a reasonable estimate of body fat; however, BMI doesn't directly measures body fat. So some people such as muscular athletes may have a BMI in the obese category even though they don't have excess body fat.[5]

\section{Risk factors of obesity}

- Genetics - genes may affect the amount of body fat you store and where that fat is distributed. Genetics may also play a role in how efficiently your body converts food into energy and however body burns calories during exercise.

- Family lifestyle- obesity tends to run in families and if one or both of your parents are obese your risk of being obese is increased that not just because of genetics. 
- Inactivity - if a person not very active and don't burn as many calories with a sedentary lifestyles. it can easily take in more calories every day than you burn through exercise and routine daily activities that having medical problems such as arthritis.

- Unhealthy diets- A diets that is high in calories lacking in fruits and vegetable full of fast food and laden with high calories beverage and oversized.

- Medical problems - in some people obesity can be traced to a medical cause such as prader wily syndrome, Cushing syndrome and other conditions, medical problems such as arthritis also can be lead to decreased activity.[6]

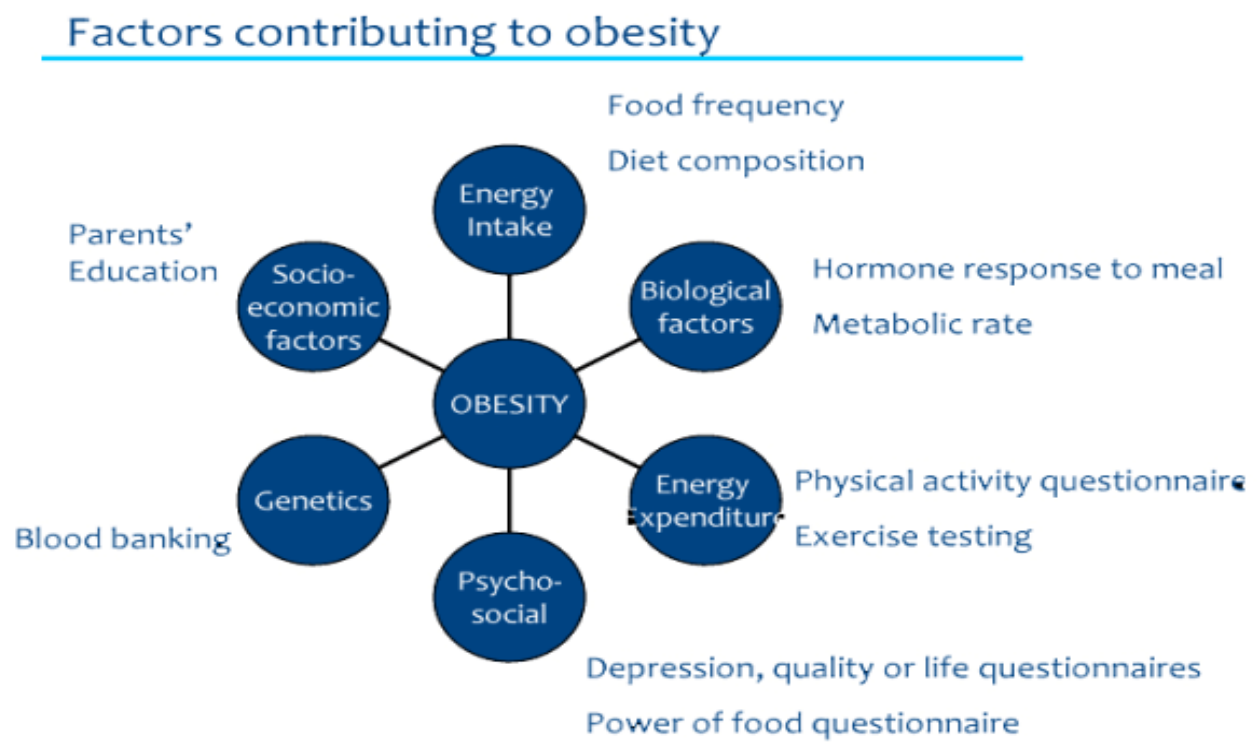

- Certain medications- some medication can be lead to weight gain if you don't compensate through diet or activity. These medications include some antidepressants and anti seizure medications.

- Social and economic issues- Research has linked social and economic factors to obesity that avoiding obesity is difficult if you don't have safe ares to exercise. May not have been taught healthy ways of cooking or may not have to buy healthier foods.

- Ages - obesity can occur at any ages even in young age's children but as hormonal changes and a less active lifestyle increase risk of obesity. In addition, the amount of muscle in your body tends to decrease with ages, this lower muscles mass leads to a decrease with 
age in metabolism. These changes also reduce calories needs and can make it harder to keep off excess weight.[7]

- Pregnancy- During pregnancy a women weight necessarily some women find this weight difficult to lose after the baby is born, this weight gain may be contributing to the development of obesity in women.

- Quitting smoking- quitting smoking is often associated with weight gains, and for some it can lead to weight gain that the people become obsess in the long run.

- Lack of sleep- not getting enough sleep or getting enough sleep can changes in hormone that increase your appetite, may also crave foods high in calories and carbohydrates.[8]

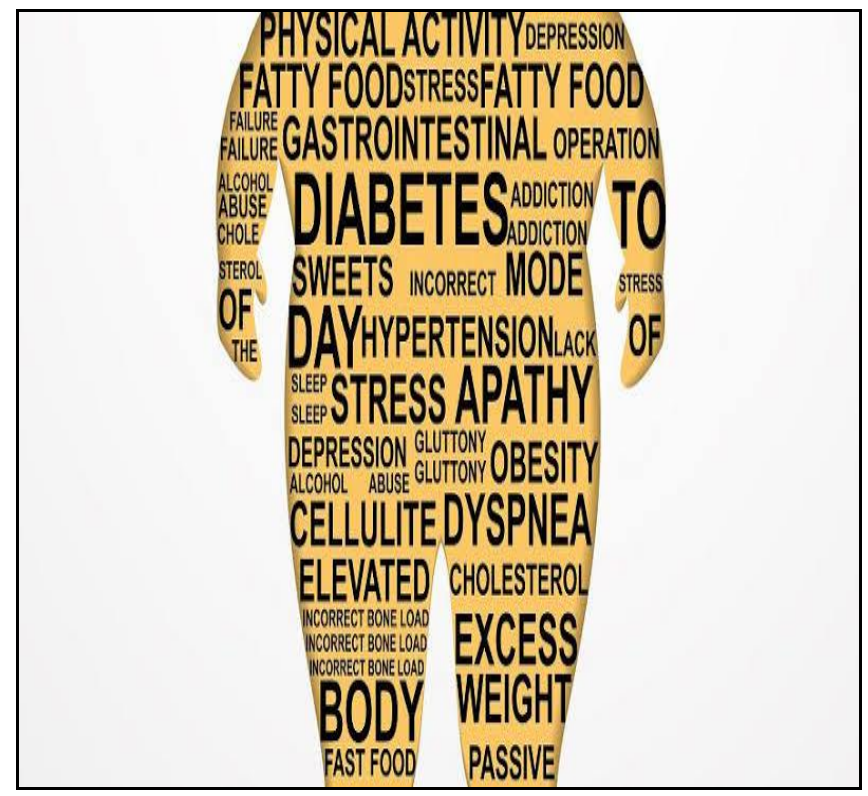

\section{Complication of obesity}

$\checkmark$ High triglycerides and low high density lipoprotein

$\checkmark$ Types 2 diabetes

$\checkmark$ High blood pressure

$\checkmark$ Metabolic syndrome

$\checkmark$ Heart disease

$\checkmark$ Strokes 
$\checkmark$ Cancer including cancer of uterus, cervix, ovaries, breast, colon, rectum, liver, kidney

$\checkmark$ Breathing disorder, including sleeping apnea, a potentially sleep disorder in which cause breathing problems

\section{$\checkmark$ Gallbladder disease}

$\checkmark$ Gynecological problems, irregular periods

\section{$\checkmark$ Osteoarthritis [9]}

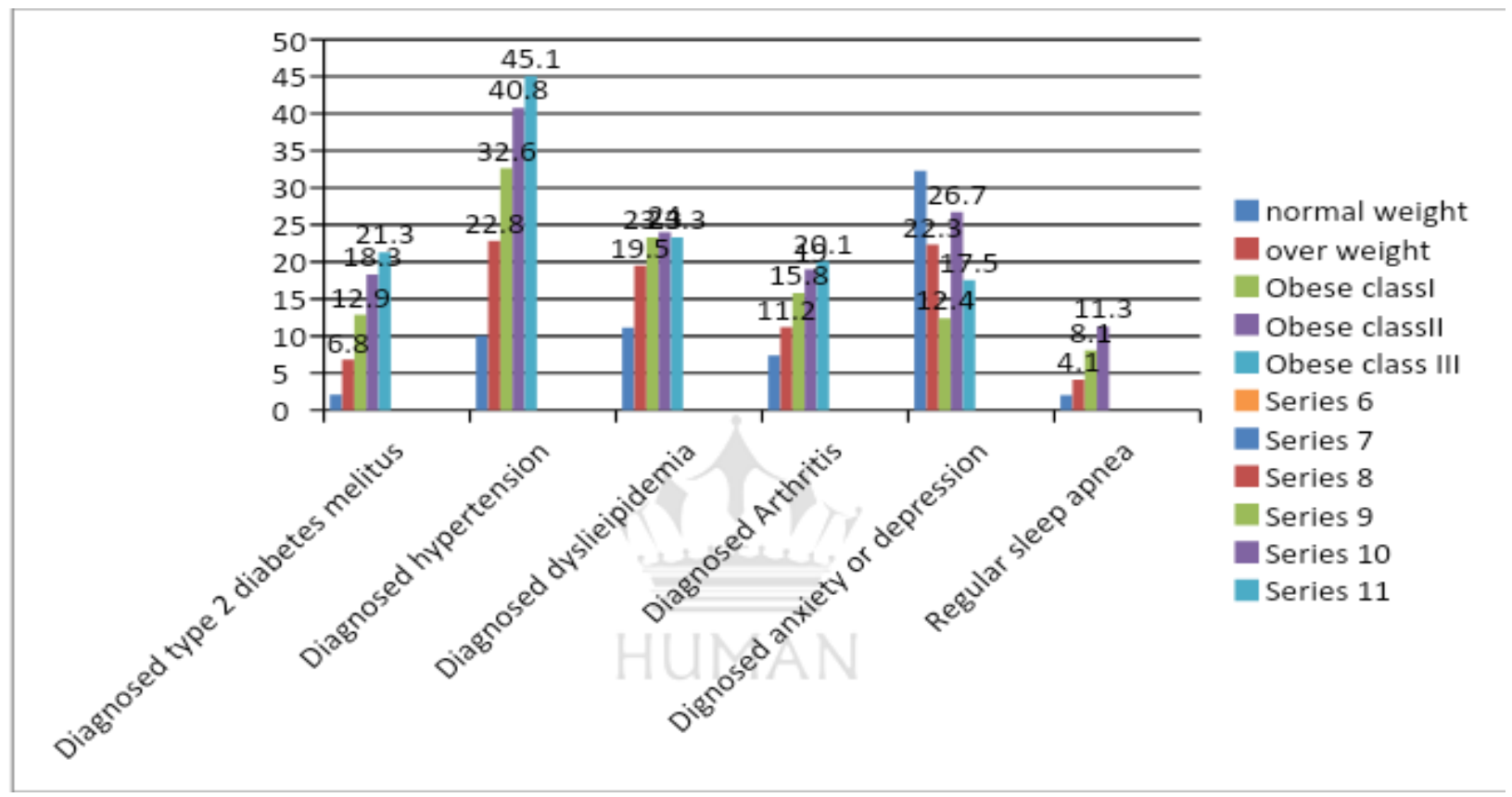

\section{Various stages of obesity}

In adults obesity can be defined as condition of abnormal of fat accumulations in adipose tissues, to extent that healthy may be impaired body mass which is consider most useful populations levels of obesity.

It is simple index to classify underweight and overweight of obesity in adults, the WHO has classified overweight and underweight in obesity of an adults based on BMI cutoff basis of obesity in classified the population.

There are ethnic variation in association of the obesity between adiposity and health care that of Asian population are generally more susceptibility to development of obesity related illness and morbidity.[10] 
In children and adolescents

Overweight and obesity in children and adolescents is complicated s height is still increasing and body composition changes over time. Different measures and refer such as weight for height, BMI has been increasingly accepted as a valid indirect measure of adiposity in children and adolescent that should be weight of gain is observed obesity.[11]

From 2004 WHO released two new sets of growth standards for infants and young children and school aged children and adolescent respectively. The standard for infants and young children was developed based fed children from around the world.

\section{In Elderly}

Body composition changes and height decrease that affecting the interpretation of anthropometric data of obesity. In our country, to the young and middle aged population numerous studies have reported that relationship between BMI and mortality in older adult and underweight, obesity might be protective for older adults.

The association between adults values for overweight and certain adverse health outcomes in elderly populations showing conflicting results with a suggestion that higher values may not results in adverse health outcomes, it may not be results appropriate to apply existing adults values may not be elder people aged 70 across and over aged. [12]

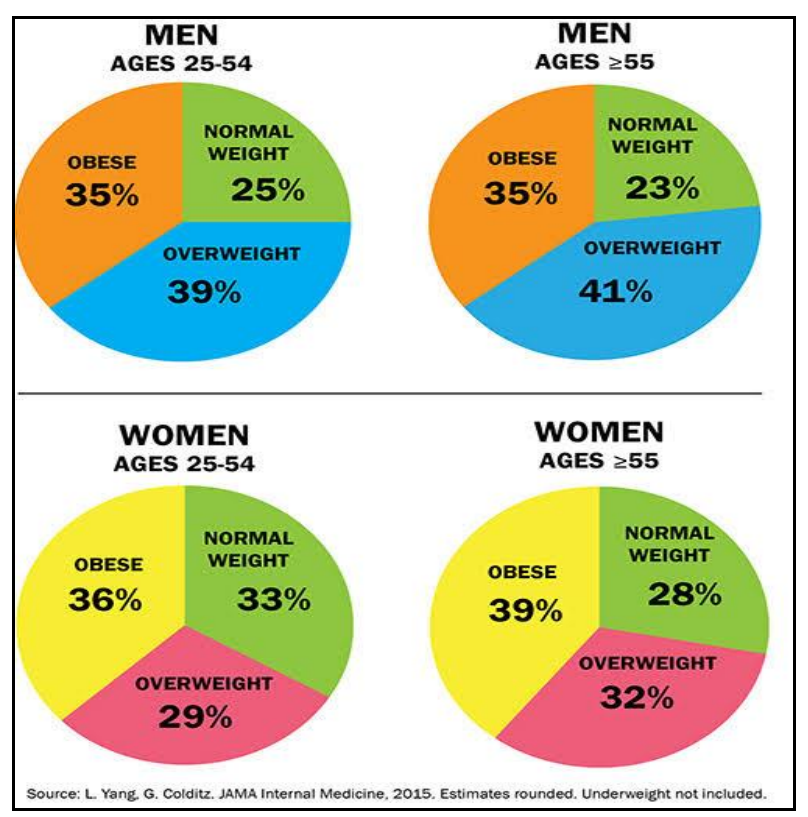




\section{Correlation with economic and obesity}

The most obese countries in the world are not necessarily the richest or the most developed, the USA and UK which are ranked $12^{\text {th }}$ and $36^{\text {th }}$ respectively between obesity and a country economic status, in fact, countries with smaller economic.

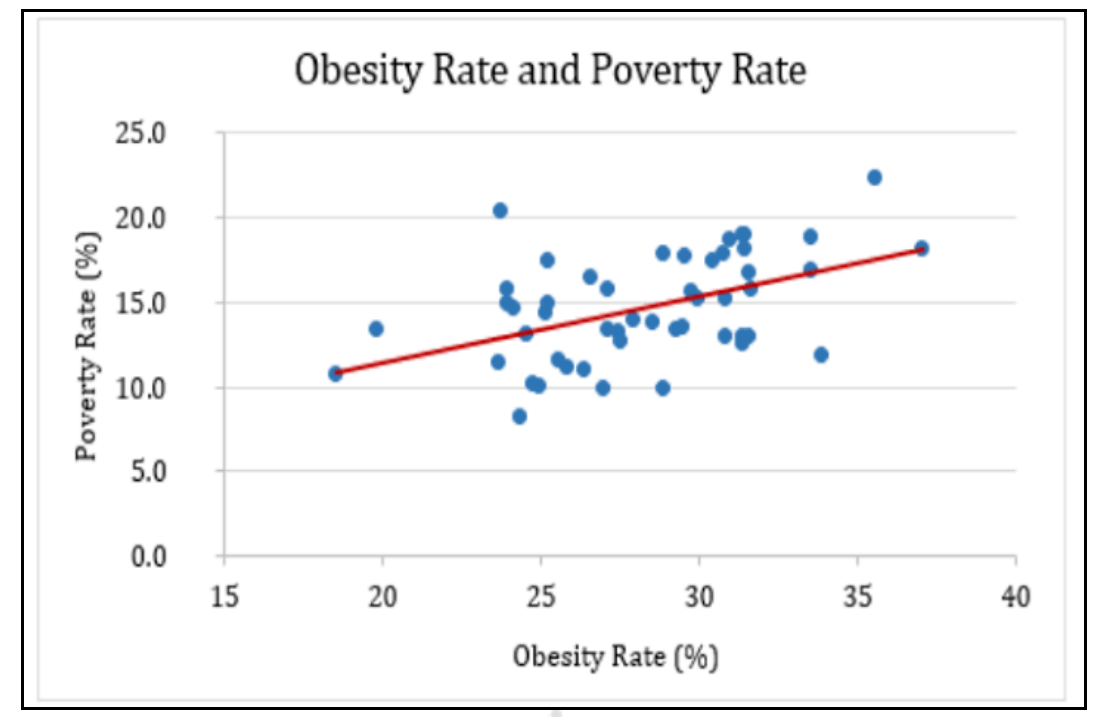

As per world health organization food scarcity and its rising prices are also responsible for obesity in underdeveloped nations such as Venezuela, where the public finds it's difficult to eat a balanced and healthy diet.[13]

Though America is not the most obese country in the world, North America still continue to lead the charts while a majority of the other countries that top of the list are small and sparsely populated countries, Mexico and US continue to top the list in the recent year treading spot for the number of 1 in North America, the united states America is the most obesity country in North America with $36.7 \%$ of its population having the body mass index of over 30.0 nearly 67 million children in the united states America deals with health and obesity effects of everyday. [14] 
www.ijppr.humanjournals.com

World obesity rates

\begin{tabular}{|c|c|c|}
\hline Rank & Country & opulation in obesity \\
\hline 1 & Nauru & 61.0 \\
\hline 2 & cook island & 55.9 \\
\hline 3 & Marshall island & 55.3 \\
\hline 4 & Palau & 52.6 \\
\hline 5 & Tuvalu & 51.5 \\
\hline 6 & Niue & 50.4 \\
\hline 7 & Tonga & 48.3 \\
\hline 8 & Samoa & 47.5 \\
\hline 9 & Kiribati & 46.2 \\
\hline 10 & Micronesia & 45.4 \\
\hline 11 & Kuwait & 37.6 \\
\hline 12 & $H U$ USA $A$ & 36.3 \\
\hline 13 & Jordan & 35.6 \\
\hline 14 & Saudi Arabia & 34.4 \\
\hline 15 & Qatar & 43.5 \\
\hline 16 & Libya & 32.4 \\
\hline 16 & Turkey & 32.2 \\
\hline 17 & Egypt & 32.0 \\
\hline 18 & Lebanon & 32.0 \\
\hline 19 & United Arabia Emirates & 31.2 \\
\hline 20 & New Zealand & 30.8 \\
\hline
\end{tabular}




\section{www.ijppr.humanjournals.com}

\section{Worldwide obesity as epidemic}

Obesity is a serious health problem of $21^{\text {st }}$ century and is an important cause of morbidity and mortality in adults as well as adolescents and children.[15]

The prevalence of obesity has reached epidemic proportions in many countries around the world and as per WHO estimates, more than the one billion adults are overweight and over 300 billion are obese.

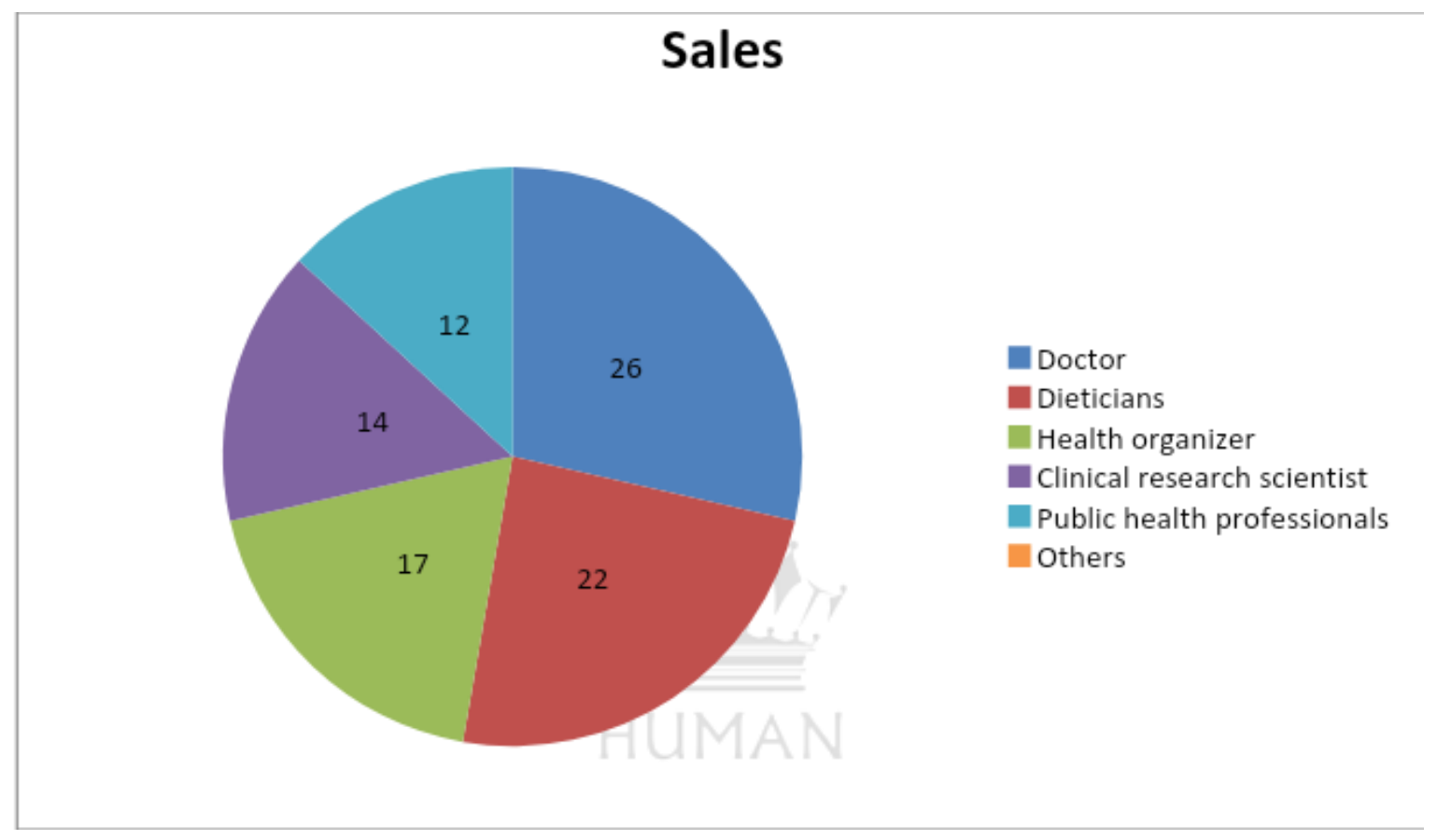

Obesity represents is a major epidemic s its prevalence is increasing both in developed and developing countries, the rising prevalence is an is issues of great concern in particularly in children due to adverse health problems associated with it. [16]

Obesity in nearly every years of life increase the risk of obesity in later life with a higher risk of developing type 2 diabetes, cardiovascular, metabolic syndrome.

Obesity is considered a multifunction and heterogeneous disease due to the complex interaction of genetic and environmental factors that studies involving genetic and molecular analysis of obesity have identified major genes involved in the regulation of energy expenditure and energy intake.

The traditional treatment and public health interaction aimed of the reducing the incidence of obesity are proving inadequate in controlling the global epidemic of this condition, all 
countries are searching for the answer of about how to reverse the rising tide of adults and childhood obesity.[17]

\section{Health consequence of obesity}

Numerous epidemiological studies have been done concluded between excess weight and abdominal fatness and risk of a range in illness.

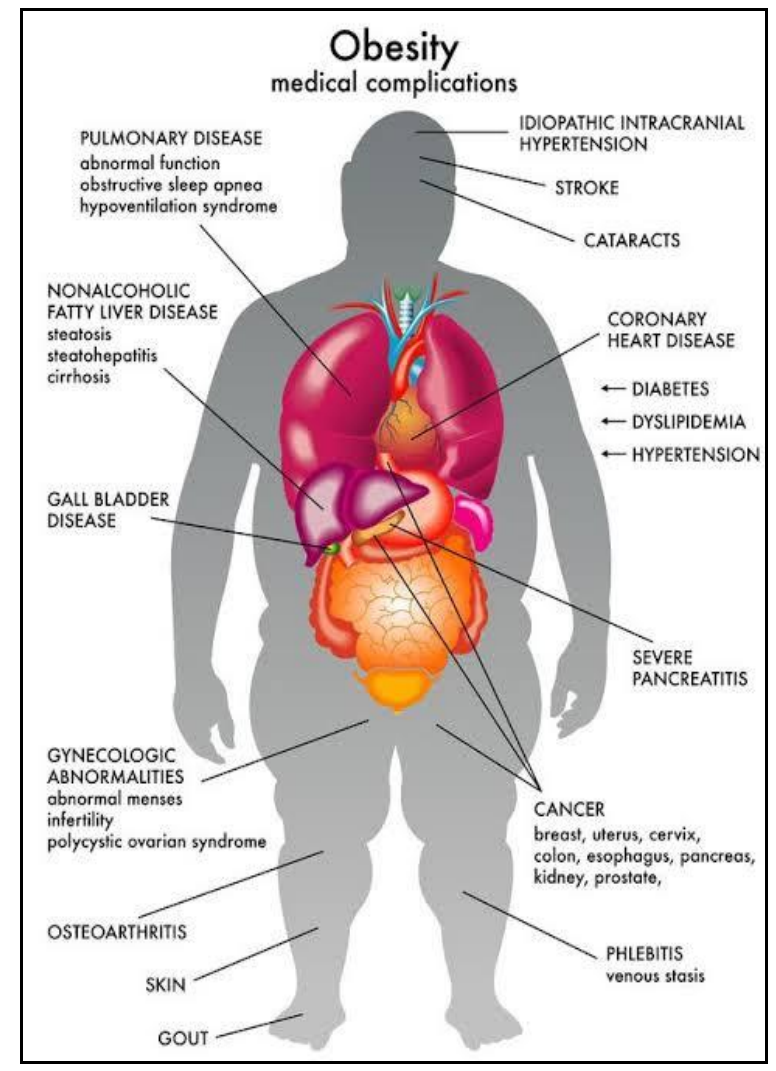

Diabetes

Type 2 diabetes has the strongest association with obesity. A meta analysis examined the relative risk of incidence of various co-related to obesity and overweight from 67 studies that are elevated BMI and WC that are significantly associated with incidence of the type 2 diabetes in men and women.[18]

Cardiovascular disease

Obesity is an individual to a number of the cardiovascular risk and including hypertension and coronary heart disease, in multiple study of atherosclerosis which is assessed the 


\section{www.ijppr.humanjournals.com}

association between obesity and cardiovascular risk factors and subclinical vascular disease in 6813 persons aged 45 to 87 years.

\section{Cancers}

The association of obesity and cancer data from a Meta analysis showed that the pooled relative risks across categories of BMI for various cancers ranged from 1.05-3.44 in women. The recent report by world cancer research funds and America Institute for cancer research 2007 also suggested that there was convincing evidence that overweight and obesity increased the risk of cancer of obesity.[19]

\section{Preventions}

Currently overweight or at healthy weight can take steps to prevent unhealthy weight gain and related health problems, the support steps to prevent weight gain are the same as the steps to prevent daily exercise.

Exercise regularly

Need to get 150 to 300 minutes of moderate intensity activity a week to prevent weight gain. Moderately intense physical activities include fast walking and swimming.[20]

Healthy eating plan

Focus on the low calories, nutrient-dense foods such as fruits, vegetable and whole grains that avoid saturated fat and limit sweets and alcohol, eat three regular meals a day with limited snacking can still enjoy small amounts of high fat, high calories foods as an infrequent treat.

Avoid the foods traps that cause you to eat

Identify situations that triggers out of controls eating, try keeping a journal and write downs what you eat, how much eat, when you eat, after a while, you should be see patterns emerge. And can plan ahead and develop strategies for handling these situations.[21] 


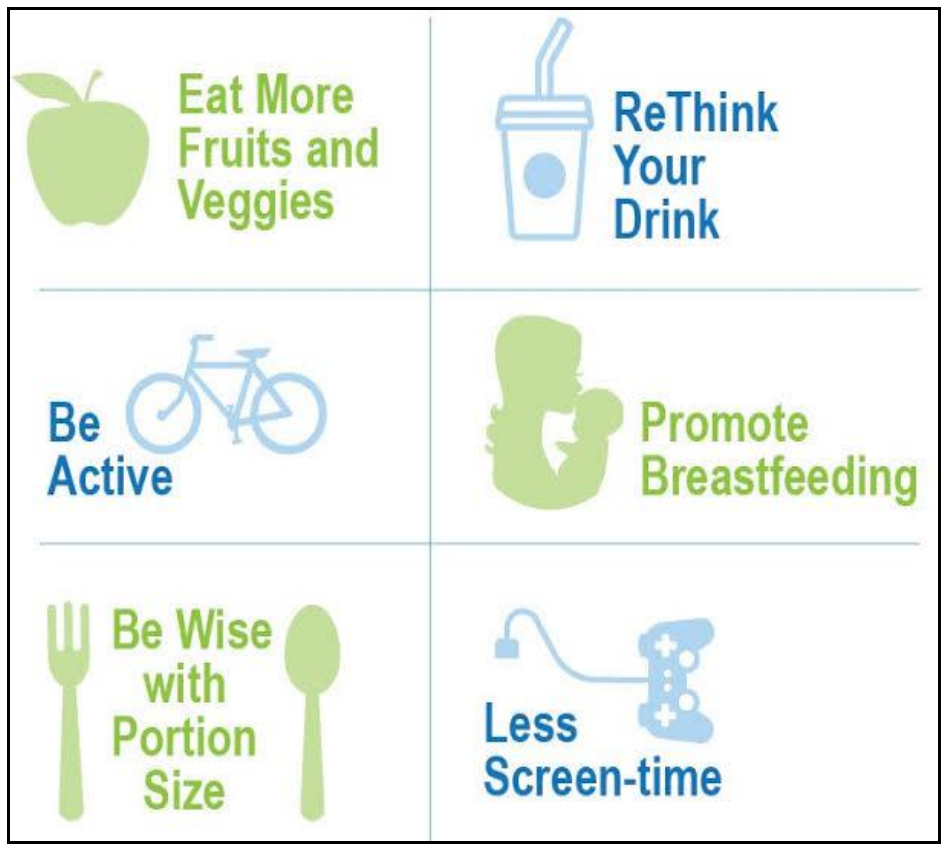

Monitor weight regularly

People who weigh themselves at least once a week are more successful in keeping off excess pounds. Monitoring yours efforts are working and can help to detect small weight gains before facing the big problems of obesity.

Be consistent.

Sticking to healthy weight plan during the week on the weekends and amidst vacations and holiday as much as possible increase yours chance of long term success.[22]

Pathogenesis of obesity

The pathogenesis of obesity is complex and involve humoral and neuronal mechanism that control appetite and safety, these stimulation responds to genetics, nutritional and environmental or psychological signals and triggers centers in the hypothalamus, the nutritional mechanism that regulate the energy balance is divided into three components.

The peripheral or afferents systems that create signal from various sites, these include leptin and adiponectin that are produced by fat cells. Ghrelin from stomach and peptide YY from ileum and colon and insulin from pancreas.[23] 


\section{Treatment of Obesity}

Obesity can be treated by three ways according to the severity of the disease. These are such as:-Surgery

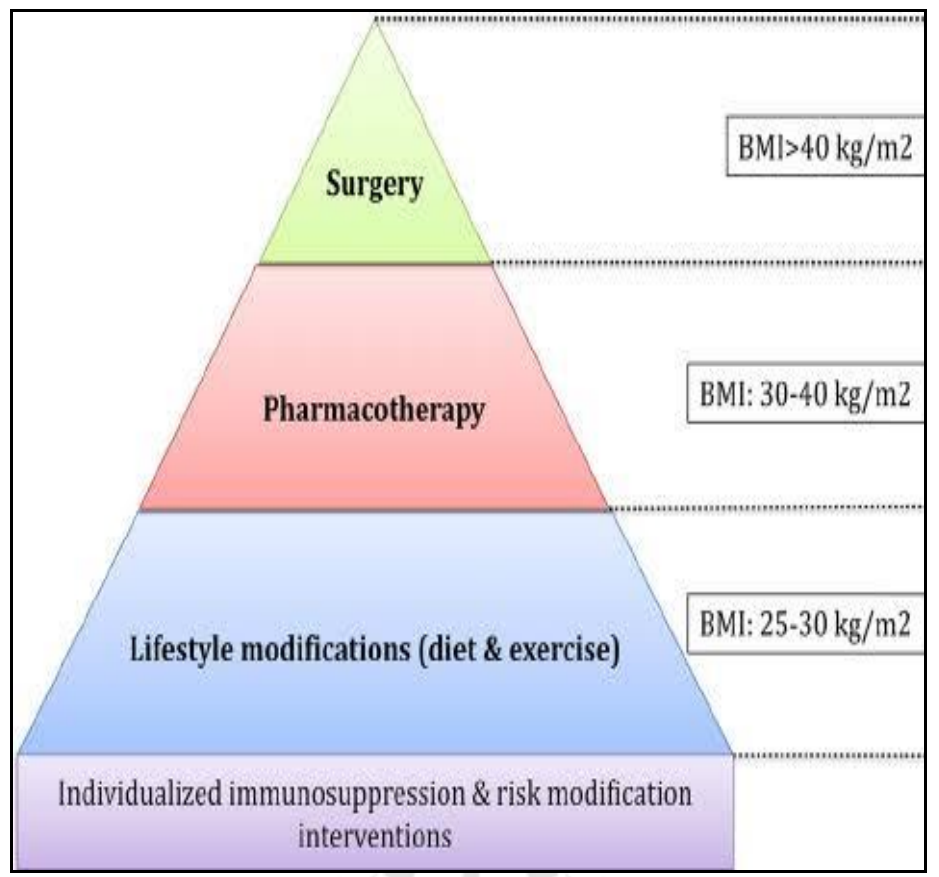

If the $\mathrm{BMI}$ of the individual is $40 \mathrm{~kg} / \mathrm{m}^{2}$ or more than 40 then tat condition will be treated by Bariatric surgery. It has not that satisfactory result but when the patient unable to do the first two they go for surgery. The Bariatric surgery can be done by two procedures such as vertical banded gastroplasty (VBG) and gastric bypass (GB).[24]

\section{Medication}

If the BMI is between 30 to $40 \mathrm{~kg} / \mathrm{m}^{2}$, then the should have to take medications for the treatment. Generally, two medications_-sibutramine (Meridia) and orlistat (Xenical) — are prescribed by the doctors or dieticiasto reduce and maintain the weight. [25]

\section{Changes in Lifestyle}

If the BMI of the patient is less than $30 \mathrm{~kg} / \mathrm{m}^{2}$, then the treatment is by some modifications in lifestyle i. e.by changing food type and by doing some physical activities. Lifestyle modification and dieting are different things. Dieting implies adhering to a particular regimen for a discrete period of time, whereas lifestyle modification involves implementing dietary 
and behavioral changes that can be sustained indefinitely to promote health. Low calorie diets should be taken for creating a negetive energy balance.[26]

\section{CONCLUSIONS}

Obesity is an important public health problems in both developing and developed countries, it. [27] increase morbidity and mortality in the different disease association both among child and adults and in both sexes. Strict diets control in relation to height and weight of the individual ages, physical activity and less intake of chunk and high calories food and increased consumption of vegetable, antioxidant, polyunsaturated fat will be decrease the incidence of obesity.[28]

The health risk and health care costs associated with overweight and obesity are considerable. The etiology of obesity is multifactorial, involving complex interaction among genetics backgrounds, hormone and different social and environmental factors.[29]

A public approach to develop population based strategies for the prevention of excess weight gains should be target factors contributing to obesity, the prevention and reduction of overweight and obesity depends ultimately on individual lifestyle changes and further research on the motivations for behavior changes to be important for changing obesity epidemic.[30]

\section{REFERENCES}

1. World Health Organization. Fact sheet: obesity and overweight. Available online: http://www.who.int/mediacentre/factsheets/fs311/en/ (accessed on 5 October 2009).

2. Gill, T. Epidemiology and health impact of obesity: an Asia Pacific perspective. Asia Pacific J. Clin. Nutr. 2006, 15, 3-14.

3. Low, S.; Chin, M.C.; Deurenberg-Yap, M. Review on epidemic of obesity. Ann. Acad. Med., Singapore 2009, 38, 57-59.

4. Asia Pacific Cohort Studies Collaboration. The burden of overweight and obesity in the Asia Pacific region. Obes. Rev. 2007, 8, 191-196.

5. Brown, W.V.; Fujioka, K.; Wilson, P.W.; Woodworth, K.A. Obesity: why be concerned? Am. J. Med. 2009, 122, S4-11.

6. Guh, D.P.; Zhang, W.; Bansback, N.; Amarsi, Z.; Birmingham, C.L.; Anis, A.H. The incidence of comorbidities related to obesity and overweight: a systematic review and meta-analysis. BMC Public Health 2009, 9,88 .

7. Yach, D.; Stuckler, D.; Brownell, K.D. Epidemiologic and economic consequences of the global epidemics of obesity and diabetes. Nature Med. 2006, 12, 62-66.

8. Muller-Riemenschneider, F.; Reinhold, T.; Berghofer, A.; Willich, S.N. Health-economic burden of obesity in Europe. Eur. J. Epidemiol. 2008, 23, 499-509.

9. Zhao, W.; Zhai, Y.; Hu, J.; Wang, J.; Yang, Z.; Kong, L.; Chen, C. Economic burden of obesity-related chronic diseases in Mainland China. Obes. Rev. 2008, 9, 62-67. 
10. Anis, A.H.; Zhang, W.; Bansback, N.; Guh, D.P.; Amarsi, Z.; Birmingham, C.L. Obesity and overweight in Canada: an updated cost-of-illness study. Obes. Rev. 2009, doi: 10.1111/j.1467-789X.2009.00579.x .

11.WHO Technical Report Series 894 Obesity: Preventing and Managing The Global Epidemic. World Health Organization: Geneva, Switzerland, 2000.

12. Garrow, J.S. Treat Obesity Seriously — a Clinical Manual; Churchill Livingstone: Edinburgh, Scotland, UK, 1981.

13.Klein, S.; Allison, D.B.; Heymsfield, S.B.; Kelley, D.E.; Leibel, R.L.; Nonas, C.; Kahn, R. Waist circumference and cardiometabolic risk: a consensus statement from Shaping America's Health: Association for Weight Management and Obesity Prevention; NAASO, The Obesity Society; the American Society for Nutrition; and the American Diabetes Association. Am. J. Clin. Nutr. 2007, 85, 1197-1202.

14.Wang, J.W.; Hu, D.Y.; Sun, Y.H.; Wang, J.H.; Wang, G.L.; Xie, J.; Zhou, Z.Q. Obesity criteria for identifying metabolic risks. Asia Pac. J. Clin. Nutr. 2009, 18, 105-113.

15. Hsieh, S.D.; Muto, T. Metabolic syndrome in Japanese men and women with special reference to the anthropometric criteria for the assessment of obesity: Proposal to use the waist-to-height ratio. Prev. Med. 2006, 42, 135-139.

16. Vazquez, G.; Duval, S.; Jacobs, D.R., Jr.; Silventoinen, K. Comparison of body mass index, waist circumference, and waist/hip ratio in predicting incident diabetes: a meta-analysis. Epidemiologic Rev. 2007, 29, 115-128.

17. Welborn, T.A.; Dhaliwal, S.S. Preferred clinical measures of central obesity for predicting mortality. Eur. J. Clin. Nutr. 2007, 61, 1373-1379.

18. Bjorntorp, P. The associations between obesity, adipose tissue distribution and disease. Acta Med. Scand. Supplementum 1988, 723, 121-134.

19.Han, T.S.; Seidell, J.C.; Currall, J.E.; Morrison, C.E.; Deurenberg, P.; Lean, M.E. The influences of height and age on waist circumference as an index of adiposity in adults. Int. J. Obes. Related Metab. Disord.: J. Int. Assoc. Study Obes. 1997, 21, 83-89.

20. Ashwell, M. Obesity risk: importance of the waist-to-height ratio. Nurs. Stand. 2009, 23, 49-54; quiz 55.

21.Han, T.S.; Bijnen, F.C.; Lean, M.E.; Seidell, J.C. Separate associations of waist and hip circumference with lifestyle factors. Int. J. Epidemiol. 1998, 27, 422-430.

22.Despres, J.P.; Moorjani, S.; Lupien, P.J.; Tremblay, A.; Nadeau, A.; Bouchard, C. Regional distribution of body fat, plasma lipoproteins, and cardiovascular disease. Arteriosclerosis 1990, 10, 497-511.

23. Despres, J.P. Health consequences of visceral obesity. Ann. Med. 2001, 33, 534-541.

24.Han, T.S.; van Leer, E.M.; Seidell, J.C.; Lean, M.E. Waist circumference action levels in the identification of cardiovascular risk factors: prevalence study in a random sample. BMJ 1995, 311, 1401-1405.

25.James, W.P. Assessing obesity: are ethnic differences in body mass index and waist classification criteria justified? Obes. Rev. 2005, 6, 179-181.

26.Zhu, S.; Heymsfield, S.B.; Toyoshima, H.; Wang, Z.; Pietrobelli, A.; Heshka, S. Race-ethnicityspecific waist circumference cutoffs for identifying cardiovascular disease risk factors. Am. J. Clin. Nutr. 2005, 81, 409-415.

27. Ashwell, M.; Hsieh, S.D. Six reasons why the waist-to-height ratio is a rapid and effective global indicator for health risks of obesity and how its use could simplify the international public health message on obesity. Int. J. Food Sci. Nutr. 2005, 56, 303-307.

28.Lee, C.M.; Huxley, R.R.; Wildman, R.P.; Woodward, M. Indices of abdominal obesity are better discriminators of cardiovascular risk factors than BMI: a meta-analysis. J. Clin. Epidemiol. 2008, 61, 646-653. 29. Misra, A.; Wasir, J.S.; Vikram, N.K. Waist circumference criteria for the diagnosis of abdominal obesity are not applicable uniformly to all populations and ethnic groups. Nutrition 2005, 21, 969-976.

30. Obesity in Asia Collaboration; Huxley, R.; Barzi, F.; Lee, C.M.; Lear, S.; Shaw, J.; Lam, T.H.; Caterson, I.; Azizi, F.; Patel, J.; Suriyawongpaisal, P.; Oh, S.W.; Kang, J.H.; Gill, T.; Zimmet, P.; James, P.T.; Woodward, M. Waist circumference thresholds provide an accurate and widely applicable method for the discrimination of diabetes. Diabetes Care 2007, 30, 3116-3118. 